\title{
A interligação da ciência e da fé com foco nos benefícios que essa união traz para a formação do estudante no ensino superior
}

\author{
The interconnection of science and faith with focus on \\ the benefits that this union brings to the formation of \\ students in higher education
}

\section{La interconexión de la ciencia y la fe con enfoque en los beneficios que esta unión aporta a la formación de los estudiantes en la educación superior}

Jorge Luiz Freire de Aquino*

Rogério de Assis**

\begin{abstract}
RESUMO
O presente artigo trata da interligação da ciência e da fé, com foco nos benefícios que essa união traz para a formação do estudante no ensino superior. Observa-se que grande parte dos alunos do ensino superior não tem a visão de integração e de complementaridade entre essas duas áreas do saber e isso, certamente, em nossa opinião, é uma deficiência em sua formação humana. Buscamos refletir e apontar caminhos na direção dessa integração, a fim de elucidar em que medida esses saberes se complementam. Nesse sentido, o leitor será incentivado a ter um olhar mais profundo sobre fé e ciência, sempre na direção de integração desses saberes. O humano não é só matéria, mas também não é só espírito, é um todo bastante complexo e interligado nele mesmo, no meio onde habita e se relaciona. Um aprofundamento nesse sentido certamente ajudará muito o aluno do ensino superior a se posicionar melhor em seu dia a dia.

Palavras-chave: Integração; fé; ciência.
\end{abstract}

\begin{abstract}
This article deals with the interconnection of science and faith with a focus on the benefits that this union brings to the formation of students in higher education. It is observed that most students of higher education do not have the vision of integration and complementarity between these two areas of knowledge, and this certainly is, in our opinion, a deficiency in their human formation. We seek to reflect and point the way towards this integration in order to elucidate the extent to which these knowledges complement each other. In this
\end{abstract}

* Graduado (UFRN) e Mestre em Filosofia (UFPB); Graduado (SPN), Especialista (SAET) e Mestre em Teologia (STBNB); Especialista em Direito Civil pela Universidade Cândido Mendes.

** Mestrando em Educação pela Universidade Nove de Julho, São Paulo, 2018; Especialização em Formação de Docentes para o Ensino Superior pelo Centro Universitário Assunção, São Paulo, 2015; Graduação em Teologia pela Pontifícia Faculdade de Teologia Nossa Senhora da Assunção, São Paulo, 2007; Especialização em Teologia pelo Instituto Anglicano de Estudos Teológicos, São Paulo, 2005. 
sense, the reader will be encouraged to take a deeper look at faith and science, always in the direction of integrating these knowledges. The human being is not only matter, but also is not only spirit, it is a very complex and interconnected whole in itself, in the environment where it dwells and is related. A deepening in this sense, will certainly help the student of higher education to position himself better in his day to day.

Keywords: Integration; faith; science

\section{RESUMEN}

El presente artículo trata de la interconexión de la ciencia y de la fe centrándose en los beneficios que esa unión trae para la formación del estudiante en la enseñanza superior. Se observa que gran parte de los alumnos de la enseñanza superior no tiene la visión de integración y de complementariedad entre esas dos áreas del saber, y eso ciertamente, en nuestra opinión, es una deficiencia en su formación humana. Buscamos reflexionar y apuntar caminos en la dirección de esa integración a fin de elucidar en qué medida esos saberes se complementan. En ese sentido, el lector será incentivado a tener una mirada más profunda sobre fe y ciencia, siempre en la dirección de integración de esos saberes. El humano no es sólo materia, pero tampoco es sólo espíritu, es un todo bastante complejo e interconectado en él mismo, en el medio donde habita y se relaciona. Una profundización en ese sentido, ciertamente ayudará mucho al alumno de la enseñanza superior a posicionarse mejor en su día a día.

Palabras clave: Integración; fé; ciencia.

\section{Introdução}

O presente artigo tem como objetivo abordar a interligação da ciência e da fé, com foco nos benefícios que essa união traz para a formação do estudante do ensino superior. Através de minha experiência pessoal, profissional e acadêmica, observo que muitas pessoas entendem fé e ciência não como saberes interligados, mas desconectados, o que, verifica-se, não é verdade. Apontaremos no artigo que é preciso relacionar essas duas áreas do saber. Sociólogos, antropólogos, filósofos, teólogos e médicos nos ajudarão a caminhar na direção da integração, da re-ligação de nós mesmos e dos saberes que explicitam essa re-ligação. Veremos a fé não só como um mover do coração e da emoção, mas também como um elemento da razão.

Defendemos, aqui, a tese de que a integração dos saberes é benéfica ao ser humano em geral, e, especificamente, ao estudante universitário, uma vez que ele está em uma fase formativa fulcral de sua vida. Para tanto, nos serviremos do pensamento complexo de Edgar Morin, que nos ajudará nesta tarefa. De plano, portanto, entendemos que esses dois vieses do conhecimento não são antagônicos, mas complementares. E é justamente nessa complementaridade e complexidade humana que vislumbramos os saberes advindos da tradição, desde o ventre materno, e depois adquiridos pelo meio onde vivemos, o que inclui nossa escolarização, e que moldará nossa personalidade e constantemente estará entranhado em nosso modo de ser e de agir.

Nesse sentido, não é possível que somente a ciência, ou seja, o conhecimento puramente racional de si mesmo e do mundo, nos dê todas as respostas ao longo de toda a nossa vida. 


\section{A complexidade do universo humano}

O universo humano é complexo, ou seja, é constituído por múltiplos componentes entrelaçados em múltiplas relações. Isto é também verdade quanto ao universo dos alunos do Ensino Superior. Para se entender a complexidade desses alunos, pode-se começar por buscar respostas a algumas questões: Como é seu lar? Qual a formação de seus pais e seu grau de instrução? Em que classe social estão inseridos? As respostas a estas e outras questões ajudarão no conhecimento do seu universo. E mais: estes alunos, por certo, se colocam questões fundamentais como estas: Quem sou eu? De onde venho? Para onde vou? São questões que fazem parte da mente do ser humano que busca o sentindo para a sua vida. Aos docentes do Ensino Superior, cabe instigar questões como essas, até visando fazer com que os discentes se conscientizem de sua própria realidade complexa, portanto, interligada, tal como aponta Morin:

O ser humano nos é revelado em sua complexidade: ser, ao mesmo tempo, totalmente biológico e totalmente cultural. O cérebro, por meio do qual pensamos, a boca pela qual falamos, a mão, com a qual escrevemos, são órgãos totalmente biológicos e, ao mesmo tempo, totalmente culturais (...) Nossas atividades biológicas mais elementares - comer, beber, defecar - estão estritamente ligadas a normas, proibições, valores, símbolos, mitos, ritos, ou seja, ao que há de mais especificamente cultural; nossas atividades mais culturais - falar, cantar, dançar, amar, meditar - põem em movimento nossos corpos, nossos órgãos; portanto, o cérebro (MORIN, 2002, p. 40).

Compreende-se pela citação acima que todos os aspectos da vida humana estão ligados e são complementares. O modo de ser e de agir do ser humano com o qual o docente irá lidar na universidade depende do meio em que ele está inserido.

Estes alunos são agora vistos como sujeitos. Segundo Morin (2002), a noção de sujeito é extremamente controvertida, sendo, simultaneamente, evidente e não evidente. Daí que, conforme Morin, o ser humano precisa ser conhecido em suas diversas dimensões sendo que, uma delas, é a sua dimensão espiritual. $\mathrm{Na}$ medida em que o ser humano conhece a si mesmo, ele se revela e se posiciona melhor consigo mesmo, na sociedade da qual ele é parte e no cosmos, pois acaba por se compreender parte do todo, e isso inclui, por certo, a espiritualidade.

Para esse pensador francês (MORIN, 1979, p.45-46), "Descartes viu que havia dois mundos: um que era relevante ao conhecimento objetivo, científico - o mundo dos objetos; e outro, um mundo que compete à outra forma de conhecimento, um mundo intuitivo, reflexivo - o mundo dos sujeitos". Esse dualismo precisa ser superado por outra forma de pensar. É preciso, 
diz Morin (1979), reconhecer os caracteres multidimensionais da noção de sujeito. O conceito de "sujeito" é um conceito organizacional, no sentido de que é inerente e necessário à auto-organização. O sujeito é um conceito ontológico, no sentido de que a sua afirmação individual egocêntrica é inerente e necessária à definição do ser vivo. O sujeito é um conceito existencial porque, como acabamos de ver, cada um dos seus traços constitutivos comporta uma dimensão existencial nos animais superiores. A afetividade, traço de nossa condição de mamíferos, constitui não a definição primária, mas uma das emergências supremas da qualidade de sujeito. Reconhecer isso é reconhecer que a noção de sujeito engloba elementos lógicos, organizacionais, ontológicos e existenciais (MORIN, 1979). E mais, dirige seu raciocínio para o ambiente da linguagem, da cultura e dos valores, chegando até o campo dos mitos. E eis que também aqui a ciência pode ser encontrada. A verdadeira ciência, diz Morin (1979), é aquela que chega ao conhecimento da ignorância.

Como vemos, o entendimento dessas dimensões precisa ser alcançado, não apenas com ampliação dessas visões, mas, também, com a busca das interligações entre os saberes estudados e, ao mesmo tempo, a busca pelo desenvolvimento nos alunos da disposição à interligação dos mais variados saberes. É pensando nessa integração dos saberes, e tendo em mente como os educandos apreendem o mundo, que devemos aceitar como realidade e dimensão ontológica do ser a dimensão da fé e da religião, ou seja, da prática da fé. Vasconcellos (2011, p.55) nos diz:

Com a crise da modernidade (Vattimo, 1998, p.17), com o reconhecimento da diversidade, com a emergência de novos paradigmas, com o enfoque da transdiciplinaridade, a esfera transcendente do ser humano, o fenômeno religioso - bomo religiosus, ainda que com restrições, começa a ter novamente espaço de reconhecimento e de manifestação no interior da universidade (lembrando que, na sua origem medieval, a universidade era por excelência um campo de elaboração do discurso religioso). Objetivamente, existe um expressivo número de intelectuais contemporâneos (...) que expressam sua crença em Deus (...). Aliás, se considerarmos o costume primitivo de enterrar os corpos dos pares da espécie, temos aí uma das práticas mais remotas dentre aqueles aspectos que passam a caracterizar o homem como tal. Mesmo no âmbito do saber acadêmico, há todo um campo de estudos em torno das Ciências da Religião (...) essas ações estariam incluídas nas práticas simbolizadoras (...) de produção de sentido para a existência, fator motivador da quase totalidade das práticas religiosas.

É dever do educador, conhecedor desta realidade ontológica do ser, expor o seu ponto de vista sobre os mais variados assuntos: o que ele acredita, qual a sua visão de mundo, visão esta que foi lhe formando e o forma constantemente através de seu imprinting cultural (MORIN, 2003), mas também 
de apontar outros olhares e leituras possíveis de mundo, respeitando, desse modo, as visões que não sejam iguais à sua (FREIRE, 1992).

\section{Religião, fé e teologia}

Quando nos voltamos para o entendimento do que é religião, vislumbramos que esse termo vem do latim religare, significando as atividades que religam o ser humano a Deus. Pode-se dizer que religião é a prática da fé professada através dos mais diversos segmentos religiosos.

Acerca da fé, afirma Messori (1994, p.45), que se trata, sem dúvida, de "um dom, uma graça divina. Mas dom divino é também a razão. Segundo as antigas exortações dos santos e doutores da igreja, o cristão 'crê para compreender', mas é também chamado a 'compreender para crer"'. Mas crer em que? No que dá sentido à nossa vida e nos conforta em meio aos infortúnios, dores e perdas.

Tomás de Aquino inicia sua Suma Teológica com a pergunta: "Deus existe?" [An Deo sit?]. E João Paulo II, comentando a obra de Tomás de Aquino em uma entrevista ao jornalista Messori (1994, p.48), nos dirá:

Não é somente uma questão que diz respeito à inteligência, mas é, ao mesmo tempo, uma questão que se refere a toda a existência humana. A pergunta sobre a existência de Deus se acha intimamente ligada à finalidade da existência humana. Não é só uma questão intelectual, mas também uma questão do coração humano (as raisons du coeur de Blaise Pascal). Penso que se considera injustamente, que a posição de Santo Tomás se esgote no âmbito racional (...) a inteligência é a criação mais maravilhosa de Deus, mas isto não significa de jeito algum cair em um racionalismo unilateral.

Mas, além da fé e da religião, precisamos saber o que vem a ser teologia. Esta palavra nos fala do conhecimento acerca de Deus, ao qual se chega racionalmente. Assim, segundo Marino Junior, médico neurocirurgião (2005, p. 138), "Religião é prática e teologia, conhecimento, ambas se auxiliando na verdadeira experiência espiritual". Destacando que esse "conhecimento", embora seja formal e acadêmico, está intimamente relacionado - assim como os demais conhecimentos científicos - à tradição e à cultura. A única forma de vislumbrar "teologia" como ciência no sentido acadêmico é vê-la como estudo das expressões ou das doutrinas religiosas, não de Deus. Saber disso é levar o pensamento moriniano acerca da integração dos saberes (2011) a uma aplicação consequente e redescobrir um dos saberes necessários para a educação do presente e do futuro. 


\section{Sobre o diálogo entre racionalidade e espiritualidade}

Seguramente, é importante compreender que, assim como a religião que se expressa em uma teologia é o resultado da fé - que possui aspectos valorativos ou espirituais - elaborada, também a ciência se expressa em categorias como resultado de epistemes (não no sentido foucaultiano) oriundas da empiria, da autoridade ou da reflexão.

Em que momento surgiu o conflito ou a separação entre a racionalidade e a espiritualidade? Em que pese a relação conflituosa entre a Igreja Católica e Galileu (1564), deve-se ressaltar que o que é visto nesse momento da história foi, sim, a convivência entre a ciência e a religião. E, embora as novas ideias fossem vistas como perigosas para as crenças e os poderes estabelecidos, elas não se opunham necessariamente à religião. Orivaldo Pimentel, por seu turno, nos lembra que:

No princípio da Modernidade havia espaço para que filósofos e cientistas como Blai-
se Pascal, Isaac Newton e Giambatista Vico exercessem sua atividade intelectual em
perfeita harmonia com sua fé. Vico, por exemplo, pôde terminar sua obra, Princípios
de uma Ciência Nova, com a seguinte afirmação: "Em suma, de tudo quanto nesta obra
se refletiu é de finalmente concluir-se que esta Ciência traz indivisivelmente consigo o
estudo da piedade, e que, se não formos piedosos, não poderemos ser verdadeiramente
sábios" (ALMEIDA; KNOBB; ALMEIDA, 2003, p. 313).

Assim, tanto para Galileu (1564) como para tantos outros cientistas da época, uma fé sincera poderia conviver com as descobertas da ciência. Somente mais tarde é que surgirão documentos colocando estas duas esferas da humanidade em choque. De fato, a separação entre a espiritualidade e a racionalidade - expressões da religião e da ciência - se dá de forma clara e final no período que comumente chamamos de Iluminismo. A primeira referência histórica explícita de que havia uma guerra entre a ciência e a religião nos vem de uma obra escrita por John Willian Drape (1874), intitulada History of the Conflict Between Religion and Science [História do Conflito entre Religião e Ciência]. Confrontando esse modelo dissociativo do saber, é possível afirmar algumas verdades advindas do que dissemos.

\section{A espiritualidade não é morbidez}

A espiritualidade não pode ser confundida com morbidez nem com simplismo. A espiritualidade tem total relação com a vida prática e cotidiana das pessoas. Não é alienação, mas um olhar diferente para si próprio, para com o outro e para o universo do qual o sujeito faz parte. Pode-se dizer que é um olhar mais profundo para todas as questões existenciais. Olhar 
não desconectado da razão, mas em comunhão com ela, afinal, o esforço para pensar e agir à luz da espiritualidade é também um esforço intelectual. Segundo Gould (2002, p. 12):

Não vejo como a ciência e a religião podem ser unificadas, ou mesmo sintetizadas, sob
qualquer esquema comum de explicação ou análise; mas tampouco entendo por que as
duas experiências devem ser conflitantes. A ciência tenta documentar o caráter factual
do mundo natural, desenvolvendo teorias que coordenem e expliquem esses fatos. A
religião, por sua vez, opera na esfera igualmente importante, mas completamente dife-
rente, dos desígnios, significados e valores humanos - assuntos que a esfera factual da
ciência pode até esclarecer, mas nunca solucionar.

Essa exposição é muito importante, porque cunhou uma expressão que pretende manter estas duas esferas em ambientes separados, mas preservando um diálogo respeitoso. Ainda que não defendendo os aspectos dialógicos próprios da complexidade, Gould não dissocia de forma maniqueísta, incomunicáveis e concorrentes os dois "magistérios", como o Iluminismo e o paradigma disjuntor fez. O conhecimento trazido pela religião, segundo Gould, "engloba questões de significado definitivo e de valor moral". A novidade que Gould apresenta é a perspectiva de que a vida é algo extremamente rica e variada e que uma leitura isolada da realidade, ou uma única abordagem, não poderia dar conta de todos os aspectos desta vida. Segundo Gould (2002, p.48), portanto, nenhum dos magistérios isolados pode sequer "chegar perto de englobar todas as intrigantes questões levantadas por um assunto complexo, especialmente um assunto tão rico quanto o significado de nossas relações com outras formas de vida”.

Nosso grande desafio é fazer com que esses aspectos da espiritualidade - ainda que dissociados de seu viés dogmático e institucional - venham a se envolver no processo educativo. Penso que o caminho mais natural para isso será aquele que trata da espiritualidade enquanto morada dos grandes valores da sociedade e da cultura.

Nesse viés, pode-se aproximar de Aquino, quando discorre sobre a espiritualidade, com base nas reflexões retiradas por Robert Solomon. Para ele, depois de tentar demonstrar como Hegel e Nietzsche procuraram naturalizar a espiritualidade desvencilhando-a da religião e das filosofias "sobrenaturais", Solomon nos oferece uma descrição de espiritualidade profundamente importante. Para ele espiritualidade significa "as paixões nobres e reflexivas da vida e de uma vida vivida em conformidade com essas paixões e reflexões nobres. A espiritualidade abarca o amor, a confiança, a reverência e a sabedoria, bem como os aspectos mais terríveis da vida, a tragédia e a morte" 
(SOLOMON, Apud AQUINO In Racionalidade e espiritualidade. Disponível em: <https:// revjorgeaquino.wordpress.com/2014/01/15/racionaliade-e-espiritualidade/> Acesso em 31 de out. de 2017). Destaca Aquino que, para Solomon, espiritualidade naturalizada é "amor reflexivo à vida" (SOLOMON, Apud AQUINO In Racionalidade e espiritualidade. Disponível em: < https:// revjorgeaquino.wordpress.com/2014/01/15/racionaliade-e-espiritualidade/> Acesso em 31 de out. de 2017). Ora, se é verdade que a espiritualidade é a alma da cultura, além de ser também a própria moradia dos grandes valores culturais expressos em cada sociedade, abandonamos o dualismo cartesiano que cinde os saberes para resguardar o papel da espiritualidade que - como guardiã dos valores - atua em todas as culturas na busca dos saberes, inclusive os acadêmicos.

\section{Redescobrindo os saberes da tradição}

As pessoas normalmente veem a tradição como algo ruim e ultrapassado. A própria história, ao ser dividida em períodos, associa a Idade Média à idade das "trevas", enquanto a Modernidade é ligada ao período que nos trouxe o Aufklärung, o Esclarecimento, as luzes e a possibilidade de um homem emancipado. Pensando assim, é translúcido o preconceito próprio de uma era na qual o paradigma disjuntor prevalece na vida e no conhecimento. Contudo, é preciso repensar esse olhar e redescobrir os saberes da tradição, afinal, ela é a nossa história.

De acordo com Edgar Morin, somos "100\% biológicos e 100\% culturais” (MORIN, 2012). Redescobrir os saberes da tradição implica em pelo menos três rendosas consequências: 1) Reconhecer que a hiperespecialização nos dá uma leitura parcial da realidade, muito embora ela não seja contrária à tradição; 2) Resgatar dimensões anteriormente produzidas e, agora, esquecidas da humanidade, e 3) Possibilitar o redescobrimento dos valores éticos tradicionais e universais, tais como justiça, solidariedade, respeito à dignidade humana, o cuidado com o meio ambiente, entre outros, como sendo essenciais para o exercício da cidadania.

Educadores e educandos precisam compreender que estes três aspectos são não apenas importantes, mas condições sine qua non de uma educação que pretenda responder às demandas cada vez mais complexas da sociedade.

Dessa forma, quando fazemos referência aos saberes da tradição, queremos falar de uma espécie de saber que foi associado com aquelas formas de ensino ligadas a um período pré-científico da formação humana e que era transmitido oralmente, por canais ligados à religião e à família. Este tipo de saber foi, e vem sendo, desvalorizado justamente porque antecede ao que 
se chama de modernidade. Como se o antigo tivesse, necessariamente, que se associar ao errado. Estamos falando daquilo que Foucault (2002, p. 506) chama de "outras configurações do saber", que, conquanto não possuam os critérios formais de um conhecimento científico, "pertencem, contudo, ao domínio positivo do saber”. Segundo Foucault (2002, p. 506):

Seria, portanto, tão vão e injusto analisá-las como fenômeno de opinião, quanto confrontá-las, pela história ou pela crítica, com as formações propriamente científicas (...) É preciso recolocá-las ao nível da positividade que as torna possíveis e determinar necessariamente sua forma. A arqueologia tem, pois, para com elas, duas tarefas: determinar a maneira como elas se dispõem na epistémê em que se enraízam; mostrar também em que sua configuração é radicalmente diferente daquela das ciências no sentido estrito.

Além de apresentar a importância da redescoberta dos saberes da tradição, também pretendemos denunciar o paradigma disjuntor na educação que almeja cindir e separar a ciência da religião, o cérebro do espírito e a razão do mito. Esta luta pela separação e pela disjunção tem marcado muito o trabalho teórico contemporâneo e encontrado respaldo dentro da academia.

É preciso, portanto, saber tanto o que o estudante universitário pensa, quanto o que a sociedade também pensa para que se possa construir o saber no sentido mais amplo e coletivo. Uma nova forma de pensar o conhecimento e uma nova prática de investigar a realidade em que a tradição, as crenças e opiniões de um povo são levadas em consideração no fazer e no discutir. Esta nova forma de pensar, este novo paradigma, é chamado de "complexo", não porque seja de difícil compreensão, mas porque pretende vincular, ou seja, re-unir, re-ligar, em construir um am-plexo entre o que o pensamento disjuntor dividiu e separou. Pretende fazer ver que estes itinerários, que foram apresentados como sendo excludentes, na verdade interagem e se fortalecem mutuamente.

Ademais, conforme ensinam as pesquisas sobre o tema, é preciso admitir que a tradição não diz respeito ao passado, ou a algo dado, e sim a algo vivo e que está constantemente se renovando e se apresentando diante de todos.

\section{Repensando o papel do educador e do aluno do ensino superior}

Neste mundo ambivalente e paradoxal, no qual de um lado vislumbramos as relativizações crescentes e a fluidez institucional e do outro a nostalgia de algo firme que fundamente nossa esperança, o papel do Educador e do Aluno precisa ser repensado. Quem são eles e quais são os seus papéis? Será o professor um simples transmissor de informações fadado a desaparecer depois da emergência do computador, ou será ele um facilitador na formação de 
sujeitos ativos para a sociedade? Quando se opta pela segunda possibilidade, não se pode deixar de ensinar, também, os valores éticos da tolerância, da compaixão, do pertencimento, e acima de tudo, da justiça.

Quem é o aluno e qual sua história de vida? Qual sua realidade socioeconômica, afetiva, religiosa? Quando se fala em compaixão e em tolerância, pensamos nos relacionamentos com os demais seres humanos, independentemente de sua classe social, cor, grau de instrução, sexo ou religião. Não podemos abrir mão da promoção de relacionamentos compassivos e tolerantes na própria sala de aula, nos relacionamentos interpessoais, mas também não se pode deixar de falar da ética do pertencimento em relação ao resto do planeta. Segundo Morin (2003, p.17), o individualismo não apenas significa “autonomia e emancipação, como também atomização e anonimização. A secularização significa não só a libertação dos dogmas religiosos, mas também a perda dos valores, a angústia e a incerteza".

Boa parte da crise de nossa sociedade se origina na ausência de uma formação que leve à ética e ao exercício da cidadania. Forma-se o indivíduo para o trabalho, capacitando-o a exercer seu papel na fábrica, mas esquecemos que ele é parte de um todo e que cresce na troca com o outro. Sem medo de errar, é no ensino religioso em seu sentido macro, ou seja, na re-ligação consigo mesmo, com o próximo, com o cosmos, com a natureza e com Deus, que encontraremos respostas para as questões da justiça, da economia, da má distribuição de renda e da concentração da terra.

Redescobrir as tradições é, além de reconhecer a parcialidade da hiperespecialização e resgatar dimensões esquecidas da humanidade, possibilitar o reencontro com valores esquecidos, o que torna os seres humanos mais aptos para a vida em sociedade. É na busca dos valores da tradição que o ser humano não apenas se tornará mais compassivo e tolerante, mas também contribuirá para o desenvolvimento de novos valores mundiais. O desafio está lançado ao educador e ao aluno do ensino superior comprometidos com sua realidade presente e futura.

\section{Considerações finais}

Nossas crenças e as decisões que tomamos são, todas elas, fruto de uma tradição e de valores que nos foram legados dentro de nossas famílias, nas nossas ruas, cidades, escolas e igrejas. Desconsiderar essas verdades, ou seja, que o ser humano sofre influência destes elementos, é o mesmo que dizer que habitamos na lua ou em outro lugar fora desta cidade e planeta. É afirmar que não somos seres sociais que desde sempre criaram normas e viveram sob elas. Pensar que desde sempre a fé não foi uma forma de ciência e que 
ambas atuaram de forma complementar e conexas é imaginar um outro ser que não o homo sapiens-demens que conhecemos.

O que procuramos fazer com este breve opúsculo foi instigar ou, mais assertivamente, mostrar que, por meio de pesquisas de campo realizadas e com base em fundamentação teórica, este tema, em que pesem os pré-conceitos que sofre, merece ser estudado com mais atenção.

Nessa conclusão, devemos ressaltar, por fim, que podemos afirmar que tanto a fé como a ciência são exercícios intelectuais que dialogam e se complementam. Ficou claro que somos mente, corpo e alma, e que possuímos espiritualidade. Toda pré-compreensão é preconceito e, portanto, aponta para algo que antecede o que se compreende ou se aprende. Por isso, é preciso que façamos um criterioso exame no que cremos para que tanto docentes quanto discentes nos dispamos das pré-noções - ou, nas palavras de Habermas, dos "interesses técnicos" que apenas racionalizam o conhecimento - e desse sentimento equivocado e estejamos abertos para o novo e para o vir-a-ser.

Desejamos que a sala de aula seja um local aberto para o diálogo e para a formação do sujeito nas mais diversas áreas de conhecimento. Seja a sala de aula um local de humanização através da tradição e do ensino. Seja nossa linguagem uma linguagem libertadora, uma linguagem aprendente, que realmente comunique não só os conteúdos, mas a vida.

\section{Referências bibliográficas}

ALMEIDA, M., KNOBB, M., ALMEIDA, A. (Orgs.) Polifônicas ideias: por uma ciência aberta. Porto Alegre: Sulina, 2003.

BOFF, Clodovis. Teoria do método teológico. 2. ed. Petrópolis: Vozes, 1999.

BULTMANN, Rudolf. Jesus. São Paulo: Teológica, 2005.

BRAKEMEIER, Gottfried. Ciência on religião: quem vai conduzir a história? São Leopoldo: Sinodal, 2006.

FOUCAULT, Michel. As palavras e as coisas. São Paulo: Martins Fontes, 2002.

FREIRE, Paulo. Pedagogia da esperança: um reencontro com a pedagogia do oprimido. 23. ed. Rio de Janeiro; São Paulo: Paz e Terra, 2016.

GOULD, S. Pilares do tempo. Rio de Janeiro: Rocco, 2002.

JEREMIAS, Joaquim. Teologia do Novo Testamento. São Paulo: Paulus; Teológica, 2004.

MASETTO. Marcos. Docência na universidade. 10. ed. Campinas: Papirus, 2009.

MARINO Jr, Raul. A religião do cérebro: as novas descobertas da neurociência a respeito da fé humana. São Paulo: Gente, 2005.

MORIN, Edgar. Método 2: A vida da vida. Porto Alegre: Sulina, 2001. . Os sete saberes necessários à educação do futuro. 2. ed. rev. São Paulo: Cortez, 2011. 
. Meus Demônios, Rio de Janeiro: Bertrand Brasil, 2002.

. O Paradigma perdido: a natureza humana. 4. ed. Publicações Europa-América. Dis-

ponível em: < http://ruipaz.pro.br/textos_pos/paradigma_perdido.pdf>. Acesso em: 29 nov. 2018.

Introdução ao pensamento complexo. Lisboa: Instituto Piaget, 2001.

McKENZIE. John L. Dicionário bíblico. 8. ed. São Paulo: Paulus, 2003.

ORDINE, Nuccio. A utilidade do inútil: um manifesto. 1. ed. Rio de Janeiro: Zahar, 2016.

PAIVA, Geraldo José de. A religião dos cientistas: uma leitura psicológica. São Paulo: Loyola, 2000.

SEVERINO. Antônio Joaquim. Metodologia do trabalho científico. 23. ed. São Paulo: Cortez, 2013.

. Filosofia na formação profissional: por que ter valores políticos, éticos e estéticos na formação profissional é importante? 1. ed. São Paulo: Cartago Editorial, 2017.

. Educação, sujeito e história. 3. ed. São Paulo: Olho d’Água, 2012.

VASCONCELLOS. Celso dos Santos. Curriculo: a atividade humana como princípio educativo. 3. ed. São Paulo: Libertad, 2011.

QUEIRUGA, Andrés T. Fim do cristianismo pré-moderno: desafios para um novo horizonte. São Paulo: Paulus, 2003.

AQUINO, Jorge. Racionalidade e espiritualidade. Disponível em: <https://revjorgeaquino.wordpress.com/2014/01/15/racionaliade-e-espiritualidade/> Acesso em 31 de out. de 2017

LOPES, Reinaldo. Desculpai, mas Jesus existiu. Folha de São Paulo. Um blog sobre teoria da evolução, ciência, religião e a terra de ninguém entre elas, 2014.

Disponível em: <http://darwinedeus.blogfolha.uol.com.br> Acesso em 20 set. 2014.

CAMPOS, Marcio. Estudantes universitários rejeitam a tese do conflito entre ciência e fé.

Gazeta do Povo. Blogs. Tubo de Ensaio. Ciência e Religião, 2011.

Disponível em: <http://www.gazetadopovo.com.br/blogs/tubo-de-ensaio/estudantes-universitarios-rejeitam-a-tese-do-conflito-entre-ciencia-e-fe/> Acesso em 20 set. 2014.

PLANTINGA. Alvin. Religião e ciência, 2011. Disponível em <http://criticanarede.com/ religiaoeciencia.html> Acesso em 20 set. 2014.

Submetido em: 12-3-2018

Aceito em: 19-12-2018 